\title{
La misión diplomática de don Pedro Ronquillo en Varsovia con motivo de la elección de Juan Sobieski como rey de Polonia en 1674
}

\author{
Miguel Conde Pazos \\ Universidad Alfonso X el Sabio \\ Instituto Universitario «La Corte en Europa»
}

\section{Resumen}

En I674 don Pedro Ronquillo viajó a Polonia para participar en la elección real. Esta misión coincidió con un momento clave en Europa, dado que la proclamación de un rey hostil a la Casa de Austria podía alterar el desarrollo de la guerra franco-holandesa. En este trabajo analizamos el papel de la diplomacia hispana durante la votación, su actuación desde diferentes cortes y la relación de Juan III Sobieski con Madrid a lo largo de los primeros años de su reinado.

Palabras clave: diplomacia, Polonia-Lituania, Juan III Sobieski, reinado de Carlos II, don Pedro Ronquillo, monarquía electiva.

\section{La missió diplomàtica de Don Pedro Ronquillo a Varsòvia amb motiu de l'elecció de Joan Sobieski com a rei de Polonia el 1674}

\section{Resum}

El I674 Don Pedro Ronquillo va viatjar a Polònia per participar en l'elecció reial. Aquesta missió va coincidir amb un moment clau a Europa, ja que l'elecció d'un rei hostil a la casa d'Àustria podia alterar el desenvolupament de la guerra francoholandesa. En aquest treball analitzarem el paper de la diplomàcia hispana durant la votació, la seva actuació des de diferents corts i la relació entre Madrid i Joan Sobieski durant els primers anys del seu regnat. 
Paraules clau: diplomàcia, Polònia-Lituània, Joan Sobieski, regnat de Carles II, Don Pedro Ronquillo, monarquia electiva.

The diplomatic mission of Don Pedro Ronquillo in Warsaw on the occasion of the election of John Sobieski as King of Poland in 1674

\begin{abstract}
In 1674, Don Pedro Ronquillo travelled to Poland to participate in the royal election. This mission coincided with a key moment in Europe, and the election of a king hostile to the House of Austria could alter the development of the Franco-Dutch War. In this paper we analyze the role of Hispanic diplomacy during the election, its intervention from different courts, and the relationship between Madrid and John Sobieski during the first years of his reign.
\end{abstract}

Keywords: Diplomacy, Poland-Lithuania, John Sobieski, reign of Carlos II, Don Pedro Ronquillo, elective monarchy.

A finales de 1673 llegó a Viena la noticia del fallecimiento de Miguel I de Polonia, cuñado del emperador Leopoldo I y uno de los principales garantes de la paz en el flanco más oriental de la Casa de Austria, fallecimiento que se había producido el ro de noviembre. El momento histórico era crucial, tanto para la confederación de Polonia-Lituania, enzarzada entonces en una guerra contra la Puerta Otomana, como para Europa en general, donde, poco a poco, la guerra franco-holandesa se iba extendiendo, con la participación cada vez mayor de todos los prín-

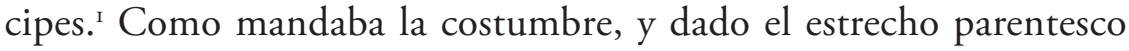
entre los dos monarcas, fue enviado de inmediato a Polonia un gentil-

I. Sobre la situación internacional del momento: Lucien BÉLy, Les relations internationales en Europe, XVIIe-XVIIIe siècles, Presses Universitaires de France, París, I99I, pp. 250-259 y Manuel Rivero Rodríguez, Diplomacia y relaciones exteriores en la Edad Moderna, I493-I794, Alianza, Madrid, 2000, pp. I46-I52. Sobre el conflicto polaco-turco: Dariusz Ko£odziejczyк, Ottoman-Polish Diplomatic Relations (IsthI8th Century): An Annotated Edition of 'ahdnames and Other Documents, Brill, Leiden, 2000, pp. I43-I52. 
hombre para dar el pésame a la viuda, la reina Leonor María Josefa de Austria. Casi al momento, llegó a Viena una nueva noticia de la zona, esta vez de un sentido muy diferente: el ejército polaco, reforzado tras la desastrosa campańa del ańo anterior, había asestado a los turcos un golpe de grandes proporciones, tras el cual estos, derrotados, dejaron sobre el campo de batalla unos treinta mil hombres, así como toda su artillería. ${ }^{2}$ Pronto, la noticia de la gran victoria en Chocim el ir de noviembre de 1673 se extendió por toda la Cristiandad, y fue transmitida por multitud de relaciones y crónicas, lo que causó un gran regocijo entre el resto de los príncipes. ${ }^{3}$ Clemente $\mathrm{X}$, por ejemplo, pidió poco después a Johann Eberhard Nithard que le felicitara de manera personal por ella y el Consejo de Estado español se declaró también partícipe de este júbilo general. ${ }^{4}$ Aquel éxito fue doblemente importante para los intereses de la Corona espańola en aquel momento ya que, como señaló el marqués de los Balbases, entonces embajador español en Viena, dificultaba cualquier ataque turco sobre Hungría al menos durante un año, de modo que garantizaba la paz en uno de los puntos más sensibles de la estrategia hispana en Europa. ${ }^{5}$

Pero el marqués también veía brumas tras aquel triunfo. La coincidencia de fechas entre la muerte del rey y la batalla, con apenas un día de diferencia, amenazaba con neutralizar el éxito, dado que la falta de autoridad durante el interregno hasta la elección del nuevo rey auguraba un período de inestabilidad dentro de la confederación, lo que creaba el marco perfecto para que los turcos pudieran rehacerse y lanzar una contraofensiva. Este peligro fue señalado por Balbases en sus primeras cartas, así como por el primado del reino, Florian Czartoryski, cuando

2. Archivo General de Simancas, Estado, (AGS, Est.), 2393, s. f., El marqués de Los Balbases, Viena, I4 de diciembre de I673.

3. Una de las primeras relaciones que llegó a la corte fue la entregada al cardenal Nithard por el cardenal Altieri: AGS, Est., 3048, s. f., Del campo de Chocim, II de noviembre de 1673 .

4. AGS, Est., 3048, s. f., El cardenal Nithard a la reina, Roma, 26 de diciembre de I673; ibidem, Consejo de Estado, I8 de enero de I674.

5. AGS, Est., 2393, El marqués de los Balbases, Viena, I4 de diciembre de I673. 
poco después notificó la muerte de su rey a Carlos II. ${ }^{6}$ Además, «el dueño de aquella victoria», como diría más tarde Balbases, no era otro que el hetman (comandante de las fuerzas de la confederación) Juan Sobieski, uno de los más destacados partidarios de Luis XIV en Polonia, cuyo prestigio y autoridad sobre el ejército podían hacer peligrar los intereses de la Casa de Austria en la próxima elección.7 Sobieski podía utilizar ambos para otorgar la corona al príncipe de Condé e incluso para alzarse él mismo con ella, como finalmente hizo.

\section{Juan Sobieski y la Monarquía Católica}

Juan Sobieski (I629-1696) es uno de los monarcas más recordados por los polacos, y su figura alcanzó cotas legendarias. Sus gestas en el campo de batalla, culminadas con la liberación de Viena de I683, hicieron de él uno de los grandes generales de la segunda mitad del siglo xviI, y sin duda fue el soberano polaco más conocido allende sus fronteras. ${ }^{8}$ También ha sido uno de los más estudiados por la historiografía, tanto nacional como extranjera, sobre todo en lo que respecta a su política exterior y a la administración y dirección de sus ejércitos. ${ }^{9}$ Pero, a pesar

6. AGS, Est., 2393, El arzobispo de Gniezno a Carlos II, Varsovia, 9 de diciembre de 1673 .

7. La corona polaco-lituana era electiva desde el año 1572, momento en el que murió el último monarca de la dinastía Jagellón sin descendencia masculina. A partir de entonces, los nobles de la confederación, junto con el clero, tuvieron el derecho de elegir a sus propios reyes, en un proceso complicado, no exento de grandes peligros, dada la falta de autoridad. Sobre este proceso: Jacek JęDRuCh, Constitutions, Elections and Legislatures of Poland, I493-1993, Hippocrene Books, Nueva York, I998, pp. 72-83.

8. Sobre la imagen cambiante de Sobieski a lo largo de los siglos: Dagnosław Demski, «Jan Sobieski. Anniversaries of the I683 Battle of Vienna (from I783 to 1983) and its Historical Imagination», Traditiones, 43 (2014), pp. 13-28.

9. Zbigniew WójcıK, "Jean Sobieski: du politicien à l'homme d'Etat», Acta Poloniae Historica, 47 (1983), pp. 5-31. La bibliografía sobre este personaje es ingente; destaca la obra de Wójcik, autor de numerosos trabajos, incluida una de las biografías más difundidas: Zbigniew Wójcıк, Jan Sobieski, Państwowy Instytut Wydawniczy, 
de la fascinación que este personaje siempre ha despertado, la historiografía española es una excepción, dado que nunca ha mostrado demasiado interés por él y menos aún se ha preocupado por escudriñar sus relaciones con la corte de Madrid. ${ }^{\circ}$ Esto no es extrańo si tenemos en cuenta la escasa atención que se ha prestado hasta hace poco a la diplomacia de Carlos II y la interpretación que durante mucho tiempo se tuvo de la posición internacional de la Monarquía durante su reinado. ${ }^{\mathrm{II}}$

El único episodio de importancia que se ha rememorado es la misión de don Pedro Ronquillo en Varsovia del año I674, que en I874 ya fue objeto de un trabajo del académico Antonio Rodríguez Villa. Esta obra es, en esencia, una recopilación de la correspondencia entre el embajador español y el marqués de los Balbases durante la elección del que habría de ser sucesor del fallecido Miguel, conservada entonces en

Varsovia, 1983. En los últimos años, sin embargo, la atención prestada a su figura ha perdido parte de su vigor, sobre todo en comparación con la dedicada a otros monarcas polacos. Además, han surgido nuevos intereses y un ejemplo lo tenemos en el trabajo de Francesca de Caprio, dedicado a la segunda mitad de su reinado, período mucho menos estudiado: Francesca De CAPrio, Il tramonto di un regno. Il declino di Jan Sobieski dopo il trionfo di Vienna, Sette Città, Viterbo, $20 \mathrm{4}$.

Io. Una excepción sería el apéndice documental realizado por Miguel Gómez Campillo para la edición de la obra de Renaud Przezdziwcki, Diplomatie et protocole à la cour de Pologne, publicada en la década de 1940 ("Los embajadores españoles en Polonia", Boletín de la Real Academia de la Historia, t. I2I, 2; t. I22., I y 2; t. I23, 2, 1947-1948). Desde Polonia, el profesor Ryszard Skowron sí mostró cierto interés por el intercambio de embajadas durante la segunda mitad del siglo XviI, si bien su trabajo se centra fundamentalmente en los reinados de los reyes Jagellón y Vasa: Ryszard Skowron, Dyplomaci polscy w Hiszpanii w XVI $i$ XVII wieku, Universitas, Cracovia, 1997.

II. Un desconocimiento que en los últimos años se ha empezado a corregir: Juan A. SÁnchez Belén, «Las relaciones internacionales de la Monarquía Hispánica durante la regencia de doña Mariana de Austria», Studia Histórica, Historia Moderna, 20 (1999), pp. I37-I72; Christopher STORRS, «La diplomacia espańola durante el reinado de Carlos II: una Edad de Oro o ¿quizá de Plata?», en P. Sanz Camañes, coord., Tiempo de cambios: guerra, diplomacia y política internacional de la Monarquia Hispánica (I648-1700), Actas, Madrid, 2012, pp. 2I-55; Miguel Ángel OchOA Brun, Historia de la diplomacia española, vol. viII, La Edad Barroca (II), Ministerio de Asuntos Exteriores y de Cooperación, Madrid, 2006, pp. 89-170. 
el archivo privado de esta última familia — hoy en día Archivo de Albuquerque- ${ }^{12}$ La obra es, por otra parte, un producto de su época. La edición y los comentarios hechos por el autor responden por completo a los parámetros imperantes entonces en la historiografía, y juzga la misión como una arriesgada iniciativa que respondió únicamente a los intereses de la reina y su familia. ${ }^{13}$ La misión de Ronquillo fue de nuevo analizada en un trabajo mucho más reciente, pero de escasa difusión: la tesis de Jesús Oyamburu Fernández sobre la carrera del embajador español. ${ }^{14}$ Esta obra aporta multitud de fuentes, procedentes en su mayoría del Archivo General de Simancas, de las cuales cabe destacar la correspondencia entre el embajador espańol y Manuel de Lira, de un tono mucho menos formal que la entablada entre este y la Corte de Madrid o con el marqués de los Balbases. ${ }^{15}$ La misión de Ronquillo también atrajo la atención de otros historiadores extranjeros, como C. Scott, que en 1962, y en colaboración con P. Skwarczyński, publicó un artículo sobre ella basándose en los documentos recogidos por Rodríguez Villa y una serie de manuscritos hallados en el Archivo General del Reino de Bruselas, la mayoría de ellos de fecha muy posterior a la embajada. Este trabajo se centra en los pormenores del viaje y la estancia de Ronquillo en Polonia, pero sobre todo, en su visión del reino, y

I2. Antonio Rodríguez Villa, Misión secreta del embajador Don Pedro Ronquillo en Polonia (1674): según sus cartas originales al marqués de los Balbases, embajador a la corte de Viena, Imprenta de las Biblioteca de Instrucción y Recreo, Madrid, I874. El principal memorial remitido a la reina fue editado en la Revista Europea, con fecha del 20 de septiembre de I874, pp. 371-379. Existe una edición en polaco de este texto: Feliks Róźański, Listy Piotra Ronquillo, Przegląd Polski, Cracovia, I878, t. 50, pp. 330-368.

13. «Atenta siempre dońa Mariana de Austria á engrandecer su imperial familia, no vacilo, llegado este caso, á truque de sostener á su hermana en el trono de Polonia, en intervenir, siquiera oficiosamente, en un asunto que apenas interesaba á España y que pudo comprometernos gravemente y crearnos trascendentales conflictos», en Rodríguez Villa, Misión secreta del embajador, pp. 8 y 9.

I4. Jesús Oyamburu Fernández, «Don Pedro Ronquillo y la diplomacia española en el norte de Europa durante el reinado de Carlos II», tesis doctoral inédita, Universidad Complutense, Madrid, I995, pp. 226-24I.

I5. AGS, Est., 8466. 
deja en un segundo plano la actividad política. ${ }^{16}$ Ninguno de estos trabajos ha profundizado en este último aspecto, ni ha analizado el papel jugado por los otros ministros de la Monarquía.

Juan Sobieski era conocido por la diplomacia espańola mucho antes de que Miguel I falleciera. Proveniente de una familia de la nobleza media de Sandomierz, en la región de la Pequeńa Polonia, su linaje había ascendido social y económicamente durante las últimas décadas del siglo XVI, bajo el liderazgo de su abuelo: Marek Sobieski (I550-I605). Este fue el primer miembro de la familia en ocupar un asiento en el Senado, lo que se debió a su talento militar y sus vínculos con el canciller Jan Zamoyski — familia con la que a partir de entonces los Sobieski estarían vinculados- - Sus sucesores se caracterizaron por sus buenos servicios a la Corona, así como por su formación humanística. El padre del futuro rey, Jakub (I580-I646), completó sus estudios en París y emprendió a continuación un periplo por Europa, que le llevó también a Espańa y a Portugal. ${ }^{17}$ El propio Juan siguió un camino similar y, junto con su hermano mayor, Marek - quien fallecería en I652, combatiendo a los cosacos-, se trasladó a Francia en I646 para completar sus estudios. Ya entonces, el futuro rey mostró un gran interés por todo lo referente a la cultura de aquel país, y entró en contacto con las ideas de los autores de la época, lo que sin duda alguna influyó en su posicionamiento posterior ${ }^{18}$ A su regreso a Polonia, a finales de la década de

I6. C. Scott y Paweł Skwarczyński, «A I7th-Century Spanish Diplomat's View of Poland», Slavonic and East European Review, xL, 95 (1962), pp. 497-517. Los textos habían sido recogidos por Francisco Antonio Navarro, secretario de Ronquillo y destacado austracista, que los pudo salvar del incendio de la embajada de Londres de I688.

17. Los diarios de este viaje, en el que no faltaron los incidentes, como un robo en Pamplona, fueron transcritos y traducidos en el siglo xIx: Javier Liske, Viajes de extranjeros por España y Portugal en los siglos XV, XVI y XVII, Casa Editorial de Medina, Madrid, I878, pp. 233-267; sobre este viaje y los orígenes de la familia: Cezary TARACHA, «The Courts of the Spanish and Austrian Habsburgs as related by Jakub Sobieski in the first half of the I7th Century», Roczniki Humanistyczne, LXI, 2 (2003), pp. I69-I82.

I8. Sobre las inquietudes intelectuales del rey, su biblioteca y su bagaje cultural: Sabina Barbara FlanczewsKa, "Zainteresowania intelektualne i bibliofilskie króla Jana III Sobieskiego", Biuletyn Biblioteki UMCS, r. 30/3I (1982-I983), pp. 7-44. 
I640, encontró un reino desgarrado por el conflicto con los cosacos y por la invasión sueca, jugando un papel activo en ambas guerras.

Durante la década de i66o Juan Sobieski se aproximó al grupo de la Corte polaca, encabezado en ese momento por la reina María Luisa de Nevers, esposa del entonces rey Juan Casimiro, de tendencias filofrancesas y reformistas. Su principal vínculo, tanto con este grupo como con la Corte de París, fue una persona integrante del séquito de la reina: María Casimira de la Grange d'Arquien (I64I-I7I6), de la cual Sobieski se enamoró. Se casaron en I665 y esta unión sancionó el alineamiento definitivo del futuro rey dentro del campo de la corte, pues fue considerado a partir de entonces como un partidario de los franceses en el reino. No en vano, Luis XIV le otorgó una pensión poco tiempo después. ${ }^{19} \mathrm{Su}$ ámbito de actuación fue primordialmente el ejército, donde cubrió el vacío dejado por el general Stefan Czarniecki, fallecido en I665, al tiempo que se contraponía al líder de la oposición, el gran mariscal Jerzy Lubomirski — cargo el de este último que Sobieski ostentaría tras la caída en desgracia de Lubomirski-. Ya entonces, Sobieski estuvo en la mira de los diplomáticos españoles, que desconfiaban de él $y$, sobre todo, de su esposa francesa. ${ }^{20}$ Durante los años siguientes, el general hubo de hacerse cargo de un ejército real mal financiado, que

19. Jean du Hamel De Breuil, "Sobieski et sa politique de I674 a I683", Revue d'Histoire Diplomatique, 7 (I893), [reimpresión: A. Pedone, ed., I967, vol. I, pp. 48I527]; Mirosław Nagielski, «"Partia dworska” w schyłkowym okresie panowania Jan Kazimierza Wazy (I664-I668)», en R. Skowron y M. Markiewicza, coords., Faworyci i opozycjoniści. Król a elity polityczne w Rzeczypospolitej XV-XVIII wieku, Cracovia, Zamek Królewski na Wawelu, 2006, pp. 33I-357; Maciej SERWAŃsKI, "Être une reine étrangère: deux Françaises en Pologne», en I. Poutrin y M. K. Schaub, dirs., Femmes et pouvoir politique. Les princesses d'Europe XVe-XVIIIe siècle, Bréal, Rosny-sous-Bois, 2007, pp. 193-200.

20. Encontramos numerosos informes provenientes de Viena en los que se cita al general, como tras la derrota de Mątwy, que a punto estuvo de provocar su caída en desgracia: AGS, Est., 2382, s. f., El conde de Castellar, Viena, 28 de diciembre de I666; Relación del estado de las cosas de Polonia como la dio a su Majestad Cesárea el conde de Colalto venido de aquella corte. 
cada vez jugaba un papel más activo en la vida política polaca. ${ }^{21}$ Como veremos más adelante, esta sería una de las claves de su futura elección. A pesar de estos problemas, Sobieski supo cosechar toda una serie de victorias contra los cosacos y los tártaros, lo que le granjeó un gran prestigio.

En la elección de 1669 estuvo entre los que respaldaron las candidaturas francesas, la de Condé y el duque de Neoburgo, pero vio frustradas sus esperanzas al ser coronado Miguel I de manera inesperada. Esta elección supuso el paso de Sobieski a la oposición, al igual que el de la gran mayoría del antiguo grupo de la corte, desde donde mantuvo actitudes de resistencia, participando en un grado u otro en las diferentes conspiraciones que se fueron sucediendo. ${ }^{22} \mathrm{Al}$ mismo tiempo, conservó contactos con agentes franceses, para los cuales muchas veces su esposa sirvió como nexo, e incluso tuvo confidencias con los rebeldes húngaros. ${ }^{23}$ A pesar de su enfrentamiento con la Corona, Sobieski reforzó su liderazgo al frente del ejército, aprovechando para ello los choques entre la corte y la oposición. El punto culminante de este conflicto llegó a principios de $\mathrm{I} 673$, tras la invasión otomana que tomó la provincia de Podolia, cuando Miguel I se vio obligado a aceptar un acuerdo con sus enemigos que ampliaba de forma considerable la autoridad del general sobre el ejército y la justicia. Pocos meses más tarde, el monarca moría y Sobieski se presentaba en el campo electoral con más prestigio que nunca y dos ideas de futuro para la confederación: la reforma de su sistema político y un cambio radical de su política exterior. ${ }^{24}$

2I. Zbigniew Hundert, "Wojsko koronne wobec elekcji I669 roku», Studia z Dziejów Wojskowosci, III (20I4), pp. 9I-II4.

22. Sobre las tensiones y luchas de facciones en aquel reinado: Joanna MATYAsiK, Obóz polityczny króla Michata Korybuta Wiśniowieckiego, Instytut Historii PAN, Varsovia, 2OII.

23. De Breuil, "Sobieski et sa politique».

24. Wójcık, «Jean Sobieski: du politicien». 


\section{2. "Uno de los negocios más importantes que oy ocurren»}

La elección de 1674 se produjo en un momento particularmente delicado dado el estado de guerra imperante en Europa, y ponía en peligro no solo los intereses de Leopoldo I en la zona, como apuntó Rodríguez Villa, sino también los de Carlos II en el continente. Desde I672, con el estallido de la guerra franco-holandesa, la Corte española había tratado de establecer una gran alianza en Europa que cercara a los franceses en Flandes. Uno de los ejes principales de esta estrategia era la Corte de Viena, donde se trabajó para reconstruir la vieja política de colaboración dinástica, rota tras el Tratado de Reparto de $1668 .{ }^{25}$ Los frutos de este empeño empezaron a notarse a lo largo de I673, cuando Leopoldo I llegó a un nuevo acuerdo con el elector de Brandemburgo y a otro con los holandeses. Estos éxitos fueron posibles gracias, en parte, al estallido de la guerra polaco-turca, que descargó cierta tensión de Hungría, territorio en aquel momento muy inestable cuya nobleza se había alzado en armas contra el gobierno de Leopoldo. El reino de Polonia jugaba un papel extremadamente importante en aquella parte, no solo porque desviaba la atención de los turcos de Hungría, sino también por los estrechos nexos y comunicaciones que mantenía con ese reino. De recaer la Corona polaca en un príncipe hostil, como Condé, o en el propio Sobieski, este tenía la posibilidad de convertir Polonia en un trampolín para las ayudas francesas a Hungría, e incluso rivalizar por su Corona. Además, un nuevo frente podía abrirse en Silesia, si se tienen en cuenta los derechos históricos que aquella Corona aún conservaba sobre este territorio. En palabras de Ronquillo, en el caso de una elección malograda:

25. Manuel Herrero Sánchez, Antonio Álvarez-Ossorio, «La aristocracia genovesa al servicio de la Monarquía Católica: el caso del III marqués de Los Balbases (I630-I699)», en M. Herrero Sánchez, Y. R. Ben Yessef Garfia, C. Bitossi, D. Puncuh, coords., Génova y la Monarquía Hispánica (I528-1713), Società Ligure di Storia Patria, Génova, 20II, pp. 33I-366; SÁNCHEZ BelÉN, Las relaciones internacionales. 
El señor Emperador se allará rodeado por todas partes de la fuerza de Francia con el pretexto de querer la Polonia recuperar la Silesia y asi yo la graduó por uno de los negocios más importantes que oy ocurren. ${ }^{26}$

Esta amenaza repercutía a su vez en el frente occidental, y podía afectar al grado de compromiso de Leopoldo en la guerra de Holanda y con ello al mantenimiento del bloque antifrancés. Ya en las primeras negociaciones, los representantes imperiales habían dejado claro que el número de ayudas y tropas desplazadas a occidente dependería de las circunstancias internas, y primaría en todo momento la conservación de los territorios propios frente a Italia o el Rhin. ${ }^{27}$ Una mayor presión de los enemigos de la casa sobre Hungría podía provocar una salida precipitada de Leopoldo del conflicto, poniendo en peligro toda la red de alianzas formada por la diplomacia espańola contra Francia; por tanto, la mera amenaza de ver un monarca hostil sentado en el trono de Varsovia podía conducir a una reversión de la política imperial última. Al fin y al cabo, el príncipe de Lobkowicz, máximo defensor de llegar a un acuerdo con Luis XIV, aún seguía en Viena y la diplomacia papal presionaba para que Leopoldo firmara la paz con Francia, abandonara a los holandeses y se centrara en la defensa de Hungría y la lucha contra el sultán. ${ }^{28}$ Desde Madrid eran conscientes de todos estos problemas y de la necesidad de respaldar tanto económica como diplomáticamente al emperador, lo que explica el envío de Ronquillo a Varsovia.

A esta cuestión había que sumar la potencial influencia que pudiera tener la elección sobre el resto de las cortes, especialmente en aquellas con las que la diplomacia espańola estaba negociando en aquel momento. Desde finales del ańo anterior, los ministros españoles en Vie-

26. AGS, Est., 8488 , f. 359, D. Pedro Ronquillo a Manuel de Lira, 4 de febrero de 1674 .

27. AGS, Est., 2487, s. f., La reina Mariana al marqués de Los Balbases, Madrid, I6 de julio de 1674 .

28. AGS, Est., 2393, s. f., Consejo de Estado, 7 de febrero de I674. Desde Roma siempre se había criticado el apoyo de Leopoldo a los holandeses, y en cambio se abandonaba a un príncipe católico, como era su cuñado Miguel, frente a los turcos. 
na, en colaboración con los imperiales y los holandeses, se habían lanzado a la búsqueda de nuevos aliados, entre los que cabía destacar al príncipe de Brunswick, al elector de Sajonia y al rey de Dinamarca. Pero el que más interés suscitaba, por el número de tropas y su cercanía a Flandes, era el elector de Brandemburgo, con quien se estaba negociando en aquel momento un nuevo acuerdo militar y la formación de un ejército de quince mil hombres. ${ }^{29}$ Federico Guillermo tenía importantes intereses en el reino polaco, tras firmar en I657 el tratado de Werhau, que le otorgaba la soberanía plena sobre la Prusia ducal, así como otras contrapartidas que los polacos ahora se resistían a reconocer. ${ }^{30} \mathrm{El}$ «Gran Elector» quería solucionar este contencioso poniendo al frente del trono polaco a un príncipe afín, motivo por el cual en un primer momento se planteó presentar a su hijo, Karl Emili, como candidato. Posteriormente, cuando este proyecto se vio abocado al fracaso, respaldó al hijo del príncipe de Neoburgo, quien se mostró dispuesto a ceder en estos contenciosos. En cierta medida, la actuación de Federico Guillermo durante los meses de la elección reflejó muy bien su forma de proceder en Europa, con su diplomacia manteniendo una postura equidistante y esquiva entre las dos grandes casas, la Austria y la Borbón, mientras que, de manera sutil, evitaba el ascenso al trono polaco de un príncipe dependiente de cualquiera de las dos. ${ }^{3 \mathrm{I}}$ Tanta ambiva-

29. AGS, Est., 2393, s. f., Consejo de Estado, 29 de junio de I674; «Traducción del Proyecto de los puntos que se han de concluir entre el señor Elector de Brandemburgo». Según este proyecto, Carlos II debía financiar un tercio de este ejército, cosa que no molestó al Consejo de Estado, porque de esta forma el elector quedaba atado a Madrid y esta era una forma de acabar con la inconstancia de este. Por otra parte, se trató de introducir un artículo secreto por el cual se impusiera como objetivo de guerra los términos de la paz de los Pirineos, no la de Aquisgrán, algo a lo que parecía estar dispuesto Federico Guillermo, siempre y cuando a cambio obtuviera beneficios proporcionales.

30. Sobre este contencioso y su desarrollo durante los años previos: Anna Kamińska, Brandenburg-Prussia and Poland. A Study in Diplomatic History (I6691672), H. G. Herder Institut, Marburgo, 1983.

3I. Sobre la intervención de los diplomáticos de Brandeburgo en la elección: Andrzej Kamieńsкi, «Działania dyplomacji brandenburskiej w Polsce podczas elekcji 1674 roku», Wieki Stare i Nowe, vIII, I3 (20I5), pp. 28-45. 
lencia, de hecho, terminó por desorientar a la diplomacia imperial, que apenas supo a qué candidatura se apoyaba desde Berlín, así como a Balbases, que terminó tildando al elector de «inconstante natural», lo que le llevó a desconfiar de sus auténticas intenciones tanto en Polonia como en la guerra de occidente. ${ }^{32}$

Federico Guillermo no fue el único príncipe en plantear su propia candidatura. De entre los potenciales aliados de la Casa de Austria, pronto destacó la del hermano del rey de Dinamarca, Georg, quien decía disponer de una gran suma para gastar — en torno a un millón de reales—. ${ }^{33}$ Para Ronquillo, al igual que para Balbases, esta podía ser una buena opción, pues acercaba a aquel rey a la Casa de Austria, ahora que Suecia parecía unirse a la guerra en el bando de Francia, siempre y cuando antes el príncipe se convirtiera al catolicismo. ${ }^{34}$ También se habló de Alessandro Farnese, en aquel momento virrey en Navarra, pero la falta de apoyo de su hermano, el duque de Parma, pronto llevó su candidatura a una vía muerta. ${ }^{35}$ De Roma también surgieron otros nombres, como el del sobrino del papa, Gaspar Altieri — posibilidad esta última que no fue tomada en serio por el Consejo de Estado-, y el de Reinaldo d'Este, promovido por los Barberini. ${ }^{36}$ Pero la persona preferida por Leopoldo fue desde el primer momento Carlos de Lorena, sobrino del duque, quien ya se había postulado sin éxito en la elección de I669. Este contaba con el respaldo en Viena de la emperatriz viuda Leonor Gonzaga-Nevers, así como en Polonia de su hija, la reina viuda Leonor María Josefa de Austria, esposa de Miguel I..7 También

32. AGS, Est., 2393, s. f., El marqués de Los Balbases, 25 de enero de 1674; ibidem, Consejos de Estado del 8 de abril y 29 de junio de 1674 .

33. Ibidem, D. Pedro Ronquillo, Viena, 22 de marzo de 1674.

34. Ibidem, D. Pedro Ronquillo, Viena, I de abril I674.

35. Ibidem, El marqués de Los Balbases, Viena, 22 de febrero de 1674.

36. AGS, Est., 3048, s. f., Consejo de Estado, I3 de marzo de I674; ibidem, Consejo de Estado, I5 de abril de 1674 .

37. Nada más conocerse la noticia de la muerte de Miguel I, la emperatriz viuda se acercó a Balbases para pedirle ayuda económica, aduciendo el vínculo fraternal entre Leonor María Josefa y la reina de Espańa. Este se excusó argumentando que no tenía medios, salvo los enviados como asistencia a Leopoldo para la guerra de Holan- 
contaba con el soporte de la Corte española, si bien esta nunca se pronunció de forma oficial a su favor, sino que expidió órdenes tanto a Ronquillo como a Balbases para que favorecieran al candidato que Leopoldo finalmente defendiera, siempre y cuando su decisión no atentara contra los intereses de la casa. Entre los motivos de apoyo al príncipe estaba el viejo deseo de la familia de casarlo con Leonor María, así como el de implicar aún más a esta Corte, y la de Varsovia, en el contencioso de Lorena, ducado ocupado por los franceses desde I670.

La opción contraria de entre las que se barajaron en Viena, así como la más adversa para los espańoles, fue la de la Casa de Neoburgo — se habló para el trono tanto del padre como del hijo, y fue este último quien tuvo más posibilidades_- Esta se presentó como una candidatura de consenso, capaz de aunar el apoyo de las Cortes de Versalles y Viena, dado que el príncipe de Neoburgo era un potentado afín a Luis XIV; pero también subordinado al emperador, por lo que, a la postre, podía resultar aceptable para Leopoldo I. Es decir, una candidatura presentada desde un prisma europeo, como la de Lorena, que en este caso apuntaba a una solución de compromiso del conflicto entre el Imperio y Francia. El de Neoburgo contaba con el apoyo del elector de Brandemburgo, que le consideraba un potentado débil, que además se había comprometido de antemano a no acometer reforma alguna en el sistema político polaco; así como de Lobkowicz, con el que mantenía estrechos vínculos de carácter personal. ${ }^{38}$ En este sentido, el respaldo desde Viena a su candidatura podía suponer una muestra de apoyo a este último ministro, lo que a su vez podía anunciar un nuevo giro de la políti-

da. AGS, Est., 2393, s. f., El marqués de Los Balbases, Viena, I4 de diciembre de I673; ibidem, Consejo de Estado, II de febrero de I674. En enero, el embajador de Leopoldo en Madrid también pidió más medios a la corte para hacer frente a los problemas de Hungría y Holanda, así como para reforzar los presidios de Baviera y Polonia y para financiar la futura elección. AGS, Est., 2393, s. f., Everaldo de Harrach a la corte, Madrid, 22 de enero de 1674.

38. AGS, Est., 2393, s. f., D. Pedro Ronquillo, Viena, 8 de marzo de I674; ibidem, El marqués de los Balbases, Viena, 8 de marzo de I674; ibidem, D. Pedro Ronquillo, Viena, 22 de febrero de 1674. 
ca imperial, esta vez en un sentido favorable a los intereses de Luis XIV en Europa.

Este recelo hacia la candidatura de Neoburgo resultó estar por completo justificado a largo plazo, al convertirse en la principal opción de Francia. Durante meses, la diplomacia de Carlos II, al igual que la del resto de los príncipes, dio por seguro el apoyo de Luis XIV a un príncipe francés, como Condé o Conti, una elección que también preferían los propios partidarios del rey de Francia en Polonia. Pero el Rey Sol debía tener igualmente en cuenta sus intereses en occidente, así como el devenir de la guerra en Holanda, y en todo momento antepuso los acontecimientos en los Países Bajos a cualquier hipotético proyecto en Polonia, como ya hizo en I669. De esta forma, y ante el peligro de perder los apoyos de las Cortes de Estocolmo y Berlín - con las que negociaba una alianza y la neutralidad respectivamente-, prefirió optar por la candidatura de Neoburgo y envió para respaldarla a Forbin de Janson, obispo de Marsella. Eso sí, el Rey Sol dejó la puerta abierta a su representante para que, ante el fracaso de esta candidatura y como medio de excluir a Lorena, este pudiera apoyar a otros pretendientes, incluso a un príncipe de sangre. Esto a largo plazo sería decisivo para el apoyo final a Juan Sobieski por parte de Francia. ${ }^{39}$

\section{Varsovia, Viena y Roma: tres espacios para la elección}

La Monarquía desplegó una gran actividad diplomática durante la elección, distribuida en diferentes niveles y adaptada a los ritmos y normativas del propio proceso. El grueso de la negociación lo llevó don Pedro Ronquillo, quien se trasladó a Polonia durante la primavera y permaneció allí prácticamente el resto del año i674. Ronquillo llevaba resi-

39. Kazimierz Klemens WALISZEwski, ed., Archiwum spraw zagranicznych francuskie do dziejów Jana Trzeciego, Nakładem Akademii Umiejętności, Cracovia, I879, I, pp. 7 y ss. («Memoire pour servir d'instruction au Sr. Evesque de Marseille allant de la part de Sa Majeste ambassadeur extraordinaire en Pologne, Versailles, 30 Mars I674"). 
diendo en Viena desde el verano del ańo anterior, cuando llegó de Flandes para reforzar a Balbases en su búsqueda de nuevos aliados. Durante los meses previos, había participado en las conversaciones con los representantes de Brandemburgo, Sajonia y Tréveris. ${ }^{40}$ Su presencia en Viena, sin embargo, no gustó del todo a Balbases, que vio en el nombramiento de Ronquillo como representante extraordinario una muestra de falta de confianza hacia su labor por parte de la Corte de Madrid, por lo que su salida hacia Polonia pudo ser conveniente en aquel momento. ${ }^{4 \mathrm{E}} \mathrm{El}$ propio Ronquillo se mostró satisfecho con su nombramiento en Polonia, que consideró un honor — siempre y cuando se viera bien respaldado económicamente-, e incluso bromeó con Lira sobre tan lejano destino:

Espero que vuestra m. no me desamparara en aquel ultimo angulo del setentrion con sus favores y cartas, que yo las solicitare continuadamente aunque los avisos ayan de ser de Bárbaros y de nombres acabados en esqui, isqui y osqui. ${ }^{42}$

Ronquillo no marchó a Polonia hasta los primeros días de abril, a pesar de que la orden de su embajada partió en enero y de que él estaba dispuesto desde marzo. Esto se debió a los preparativos que, entretanto, hizo la diplomacia imperial, así como a una enfermedad que el embajador iba arrastrando desde hacía tiempo. ${ }^{43}$ Su cometido oficial en

40. Sobre sus actividades previas en Flandes, donde ocupaba el cargo de superintendente de la justicia militar, y en Viena, antes de su misión, véase: Oyamburu, Don Pedro Ronquillo, pp. 155-255.

4I. De este recelo eran muy conscientes en Madrid, donde tras la elección, y a la hora de elegir nuevo destino para Ronquillo, excluyeron por completo Viena, al temer la reacción marqués. Eso sí, subrayaban que, a pesar de todo, durante su estancia ambos ministros habían colaborado de manera fructífera: «no obstante que han corrido en los negocios con unión y buena correspondencia». AGS, Est., 2393, s. f., Consejo de Estado, 26 de mayo de 1674.

42. AGS, Est., 8488, f. 37I, D. Pedro Ronquillo a Lira, Viena, 25 de febrero de I674; AGS, Est., 2393, s. f., D. Pedro Ronquillo a la reina, Viena, 22 de febrero de I674.

43. Enfermedad agravada sin duda por los remedios de la época. En una ocasión, por ejemplo, escribió a Lira mientras guardaba cama: «habiéndome resuelto a creer 
el reino tuvo que adaptarse a las rígidas normativas de la elección, que prohibían la presencia de representantes extranjeros durante una parte del proceso. Por ello, viajó oficialmente a Polonia con el pretexto de dar el pésame a la reina Leonor María de Austria, y pasó después a su servicio para, de esta forma, permanecer allí. ${ }^{44}$ De hecho, fue la antigua reina la que al final se convirtió en su principal apoyo, dado que el representante imperial, Christoph Leopold Schaffgotsch, se mostró en todo momento esquivo con él, resistiéndose a darle información. ${ }^{45} \mathrm{~A}$ largo plazo, sería el servicio a la reina viuda su principal cometido — tanto en la elección como después de ella-, y Ronquillo se integró en su reducido séquito tras su retiro en Toruń. Durante el proceso electivo, que se desarrolló fundamentalmente a lo largo de mayo, Ronquillo se encargó de promover la candidatura del príncipe de Lorena, cooperando para ello con el círculo de allegados de la reina, así como con un restringido número de senadores y nobles afines a la Casa de Austria. Una gran ayuda, si no la principal, fue la del primado del reino, Florian Czartoryski, quien, en ausencia del rey, ostentaba la máxima autoridad del país y contaba con el apoyo de su familia y buena parte de la nobleza de la Gran Polonia. En este sentido, su muerte, producida en pleno

que soy tan español como ahora diez años que estaba en Andalucía, también me e resuelto a sacar media arrova de sangre con que espero mańana ponerme en pie contento con que todavía mis humores soy castellano». AGS, Est., 8488, f. 37I, Ronquillo a Lira, Viena, 25 de febrero de 1674.

44. AGS, Est., 2393, s. f., D. Pedro Ronquillo, Viena, I de abril de I674; ibidem, El marqués de Los Balbases, Viena, 5 de abril de I674; AGS, Est., 2487, s. f., La reina Mariana a la reina viuda de Polonia, s. 1., 7 de enero de 1674.

45. D. Pedro Ronquillo a Balbases, Varsovia, 25 de abril de I674, en Rodríguez Villa, Misión secreta, doc. I; Sobre el embajador imperial, quien ya había participado en la elección de I669: Michał J. WiткоwsKI, «Rywalizacja mocarstw europejskich w Polsce w latach I669-I670 w ocenie cesarskiego posła Christopha Leopolda Schaffgotscha», en R. Skowron, ed., Polska wobec wielkich konfliktów w Europie. $Z$ dziejów dyplomacji i stosunków międzynarodowych $w$ XV-XVIII wieku, Societas Vistulana, Cracovia, 2009, pp. 407-442; Sobre su actividad sumamente cautelosa durante la elección: Janusz Woliński, «Poselstwo Krzysztofa Schaffgotscha na elekcję polską I674 r.», Sobótka, 7 (1952), pp. I43-I63. 
proceso electoral, marcó el giro de los acontecimientos y favoreció a Jan Sobieski. ${ }^{46}$

Ronquillo no dispuso para su misión de grandes sumas que gastar. Al contrario, incluso su ayuda de costa de 6.00o ducados, aprobada a principios de año, hubo de ser cubierta por Balbases, que sacó 7.000 reales de los subsidios remitidos por la Corte de Madrid a Leopoldo I. ${ }^{47}$ En este punto, su condición material contrastó por completo con la del enviado francés, Forbin de Janson, quien pudo ofrecer pensiones a los nobles afines y aportó finalmente 400.000 libras a la candidatura de Sobieski..$^{4} \mathrm{~A}$ pesar de todo, Ronquillo mostró una gran resolución y en uno de los momentos críticos de la elección, tras la muerte del primado, logró mantener el bloque lituano favorable a Lorena —al menos de forma transitoria-, gracias a una ayuda pedida directamente por la reina viuda de 3.000 húngaros. ${ }^{49}$ Las penurias económicas serían muy notables durante los últimos meses de su estancia en Polonia, cuando se instaló en Toruń, y eso dificultó su salida a su siguiente destino: la embajada de Londres.

Otro de los ministros implicados fue el marqués de los Balbases, que desde la embajada de Viena se encargó de coordinar toda la actividad de la diplomacia española en Europa, la cual adecuó a los deseos de la Corte imperial y al beneficio general de la Casa de Austria. Esta no

46. «Al fin la muerte del Arzobispo fue faltarnos la piedra angular del edificio, pues ha faltado su casa y toda la Gran Polonia, que de respeto amor y necesidad le seguía», D. Pedro Ronquillo a Balbases, Varsovia, 2I de mayo de I674, en RodríGueZ VILLA, Misión secreta, doc. 6.; AGS, Est., 2393, s. f., Everardo de Harrach a la corte, Madrid, 22 de enero de 1674.

47. AGS, Est., 2393, s. f., El marqués de Los Balbases, Viena, 5 de abril de I674; ibidem, Consejo de Estado, 2I de febrero de I674. No era la primera vez que se utilizaba este recurso y ya anteriormente se habían sacado I2.000 reales para financiar la negociación con los sajones. El Consejo de Estado, sin embargo, cuestionó por completo el procedimiento, señalando que el dinero salía directamente del bolsillo del emperador, por lo que juzgó prioritario su reintegro. AGS, Est. 2393, s.f., Consejo de Estado, I6 de mayo de I674.

48. Waliszewski, Archiwum spraw zagranicznych, pp. I4-I8 y 49.

49. AGS, Est., 2394, s. f., El marqués de Los Balbases, Viena, I4 de junio de I674. 
fue una tarea sencilla, dados los diferentes grupos de poder existentes dentro de la corte de Leopoldo, así como la falta de transparencia de ciertos ministros, lo que se tradujo en numerosos rumores sobre otras supuestas candidaturas. Algunos de estos rumores terminaron llegando a la propia Polonia y causaron fisuras entre los partidarios de la casa, como fue el caso de la hipotética candidatura del príncipe de Baden, respaldada por la casa de Saboya y Luis XIV de Francia, así como por algunos miembros de la Corte de Viena, la cual desorientó por completo a los agentes de la reina Leonor María en esa corte. ${ }^{50}$ Particularmente perjudicial para el quehacer de la diplomacia española fue la ya señalada falta de transparencia del representante imperial, Christoph Leopold Schaffgotsch. Este eludió asistir a una junta convocada en Viena con Ronquillo antes de partir para consensuar su proceder y, a pesar de los reiterados esfuerzos de Balbases, siguió mostrándose muy reservado con él durante la elección. ${ }^{\text {sI }}$ Ronquillo, a su vez, correspondió a esta actitud fría con una crítica acerba a su labor, achacándole una parte del fracaso de la elección. En concreto, cuestionó su actitud pasiva y confiada durante los días decisivos, cuando no tomó las medidas necesarias para prevenir el ascenso de Sobieski. Además, no le gustó que la entrega de los 3.000 húngaros a los lituanos se hiciera en nombre de Leopoldo I y no de Carlos II, cuyo prestigio quedó perjudicado. Ronquillo no fue el único en criticar al silesio y tras su regreso a Viena sonaron algunas voces que pusieron en duda su compromiso real con la candidatura de Lorena — las cuales, por otra parte, no llegaron a más—. ${ }^{22}$ Balbases

50. D. Pedro Ronquillo al marqués de Los Balbases, Varsovia, 25 de abril de I674, en Rodríguez Villa, Misión secreta, doc. I.

5I. Para ello, partió de improviso a Breslavia con la excusa de querer pasar la Pascua con su familia. El motivo fue aceptado por Ronquillo, quien tuvo que partir a Polonia sin conocer las instrucciones finales del embajador. AGS, Est., 2393, s. f., Don Pedro Ronquillo, Viena, 22 de marzo de 1674.

52. D. Pedro Ronquillo a la reina gobernadora, Varsovia, 26 de mayo de 1674 [carta publicada por Rodríguez Villa en Revista Europea, 30 (20 de septiembre de I874), pp. 37I-380]. AGS, Est., 2393, s. f., El marqués de Los Balbases, Viena, 20 de septiembre de I674. Dicha actitud se pudo deber al éxito cosechado por el embajador en I669 gracias a su actividad ambigua, que le valió el agradecimiento de Miguel I a 
contó en Viena con la colaboración de otros ministros cesáreos, entre los que cabe destacar al canciller austriaco Johann Paul Hocher y al secretario Christoff von Abele, responsables, por ejemplo, de la convocatoria de la junta antes citada. ${ }^{53}$ Por último, la intervención del marqués fue decisiva a la hora de evitar una acción precipitada por parte de Leopoldo tras la elección, como veremos que se planteó.

El último espacio de importancia de actividad fue la Corte romana, donde Johann Eberhard Nithard hizo ímprobos esfuerzos en favor de la candidatura de Lorena. ${ }^{54} \mathrm{La}$ actitud adoptada por el papa tenía una especial relevancia en aquel momento. La falta de autoridad regia experimentada en Polonia durante los años previos y el aumento del fervor religioso de los católicos - como consecuencia de las invasiones de la década previa, protagonizadas por ejércitos protestantes - habían aumentado la ya de por sí notable presencia de la Iglesia católica en los asuntos políticos del reino. Como muestra de ello, la reciente intervención del nuncio Francesco Buonvisi en la conciliación entre el rey Miguel I y la oposición. De esta forma, el papado disfrutaba de una posición privilegiada, a la que había que sumar su labor como eje central en la lucha contra el sultán — que tomaría forma una década más tarde en la Liga Santa_- Por último, estaba el clero polaco, que jugaba un papel destacado durante la elección. Este tradicionalmente respaldaba las candidaturas propuestas por la Casa de Austria, si bien se mantenía también muy atento a los dictámenes de Roma. La autoridad papal, por su parte, solía adoptar una posición ecuánime y evitaba dar su apoyo a ningún candidato concreto, lo que le permitía conservar su rol de padre común. Tal fue el caso de Clemente X en la elección de I674, en la

pesar de haber apoyado a Lorena. Sobre aquella ocasión: Wiткоwski, Rywalizacja mocarstw.

53. Dichos servicios a la otra rama no fueron gratuitos, y a finales de primavera insinuaron a Balbases que todavía esperaban una "demostración» de 6.000 taleros para cada uno de ellos. AGS, Est., 2393, s. f., Consejo de Estado, I4 de junio de I674.

54. Sobre su embajada: Julián José Lozano Navarro, "Una embajada controvertida. El padre Nithard en Roma (I670-I68I)", Roma Moderna e Contemporanea, $\mathrm{XV}, \mathrm{I}-3$ (2007), pp. 27I-29I. 
que solo pidió a los electores polacos que se decantaran por un príncipe católico, a ser posible un hombre hábil en manejo de las armas, puede que por el mal recuerdo que se tenía en este punto de Miguel I.s5

Pero, a pesar de esta postura, no tardaron en surgir rumores de toda clase. En Versalles, por ejemplo, se extendió la creencia de que el papa apoyaba la candidatura de Carlos de Lorena, quien ya había demostrado grandes cualidades militares y además se encontraba cerca del frente turco. ${ }^{56}$ Lo cierto es que también Nithard comunicó lo bien visto que estaba este príncipe entre los cardenales. ${ }^{57}$ Tampoco ayudó demasiado para sostener la imparcialidad papal la gran cantidad de nombres que se barajaron para el trono en Roma, como ya comentamos anteriormente. En este contexto, cualquier gesto por parte de la curia o de alguno de sus miembros podía ser interpretado como un respaldo velado por parte del papa, por lo que Nithard tuvo que estar atento a todo movimiento. En marzo de I674, por ejemplo, se opuso a que se enviara un estoque bendecido a Juan Sobieski en reconocimiento a su victoria en Chocim y argumentó para ello que podía ser interpretado como un menosprecio al mariscal de Lituania, al que algunas relaciones señalaban como el auténtico responsable de la victoria. ${ }^{58}$

Nithard también estuvo pendiente del proceder del nuncio en Polonia, Francesco Buonvisi. Este había llegado a Varsovia el ańo anterior, primero como enviado extraordinario y después como ordinario del Papa — habiendo ocupado antes la nunciatura de Colonia-. ${ }^{59}$ En un principio, Buonvisi había contado con la aquiescencia de la Corte es-

55. Gaetano Platania, Rzeczpospolita, Europa e Santa Sede tra intese ed ostilità. Saggi sulla Polonia del Seicento, Sette Città, Viterbo, 2000, pp. 95-II7.

56. Correspondance du nonce en France Fabrizio Spada (I674-1675), S. de Dainville-Barbiche, ed., École Française de Rome - Université pontificale grégorienne, Roma, I982, pp. 46-49, [Acta nuntiaturae gallicae, I5].

57. AGS, Est., 2393, s. f., Consejo de Estado, 7 de febrero de 1674.

58. AGS, Est., 3048, s. f., El cardenal Nithard a la reina, Roma, Io de marzo de 1674.

59. Sobre este nuncio y su misión: Gaetano Platania, «La nonciature à Cologne, Varsovie et Vienne de Francesco Buonvisi de Lucques à travers la documentation d'archives», en D. Tollet, L. Belly, eds., Guerres et paix en Europe centrale aux 
pañola y sus ministros, que lo consideraban un clérigo afín a la Casa de Austria. ${ }^{60}$ Pero esto cambió a finales de I673, cuando la embajada de Roma interceptó una supuesta carta suya para el cardenal Azzolino, en la que planteaba su apoyo a las candidaturas de Luis XIV para la próxima elección. ${ }^{6}$ Entre sus motivos se hallaba el deseo de ocupar en un futuro la nunciatura de París, para lo cual quería estar congraciado con el Rey Sol; así como ciertos beneficios que decía haber recibido de parte de la reina Cristina de Suecia, fuente desde hacía ańos de problemas para los españoles en Roma e Italia. La respuesta de la Corte de Madrid fue remitir órdenes a sus otros ministros para que se mantuvieran atentos al proceder del nuncio - teniéndose asimismo en cuenta que ya existía un enfrentamiento con el representante papal en Viena por el trato que había dado a la guerra de Holanda- y dejó, eso sí, cualquier resolución hacia él para después de la elección real. ${ }^{62}$ De la misma opinión fue Leopoldo I, mientras que el marqués de los Balbases, más contundente, sugirió que se utilizara la carta, en la que el nuncio se mostraba tan abiertamente dispuesto a tomar partido en la elección solo por sus intereses personales, para coaccionarle. ${ }^{63}$

La última labor de importancia del cardenal Nithard tuvo que ver con las décimas eclesiásticas en Italia. Estas habían sido las únicas ayudas prometidas por la Monarquía Católica para la guerra polaco-turca

époques moderne et contemporaine, Université de Paris IV - Sorbonne, París, 2003, pp. 463-506.

6o. «Hasta aquí hemos tenido por muy español a Monseñor Bombissio, Nuncio al presente en Polonia, pero se desvanece ahora este fiar». AGS, Est., 2393, s. f., Copia de carta del cardenal Nithard para el marqués de los Balbases, Roma, 25 de septiembre de I673.

6I. AGS, Est., 2393, s. f., Copia de carta de mons. Bombisio, nuncio en Polonia, al cardenal Azzolino, Varsovia, 4 de octubre de I673; ibidem, Consejo de Estado, 7 de febrero de 1674 .

62. AGS, Est., 2393, s. f., Consejo de Estado, 28 de abril de i674; ibidem, D. Pedro Ronquillo, Viena, 22 de marzo de 1674.

63. AGS, Est., 2393, s. f., Copia de carta del marqués de Los Balbases al cardenal Nithard, Viena, I7 de diciembre de I673; AGS, Est., 2487, s. f., La reina al marqués de Los Balbases, Madrid, 7 de febrero de 1674. 
— vía Viena, pues antes debían ser entregadas a Leopoldo I—, pero para ello debían ser negociadas con la curia romana. Su aprobación, sin embargo, se fue retrasando, al surgir toda una serie de discrepancias de carácter jurisdiccional entre los representantes de Carlos II y los del papa. ${ }^{64} \mathrm{La}$ muerte de Miguel I, a finales de I673, dio un valor ańadido a estas sumas, que pudieron convertirse en un instrumento valioso en la elección. ${ }^{65}$ En enero, el embajador de Leopoldo I en Madrid comunicó el envío de una persona desde Viena para respaldar a Nithard en esta cuestión, y se renovaron pocas semanas más tarde las órdenes emitidas por la corte. ${ }^{66}$ Tanto esfuerzo dio su fruto unas semanas más tarde, en marzo, cuando Nithard comunicó a la reina la concesión de estas décimas por parte del papa. ${ }^{67}$

\section{Claves y estrategias de la elección}

En esencia, la labor de la diplomacia española durante la elección fue dar apoyo de la actividad de la Corte imperial, sustentada a su vez por los partidarios de la Casa de Austria dentro de Polonia. Podemos distinguir dos etapas dentro su actividad, que corresponden a las dos dietas que requería el proceso electoral: la de convocatoria y la de elección. ${ }^{68}$

64. Esto se debió, fundamentalmente, al deseo del papa de introducir novedades respecto a los términos en los que se habían concedido durante la década previa, con Felipe IV como rey. Sobre este asunto: Archivo Histórico Nacional (AHN), Santa Sede, 72, f. 133, El rey al cardenal Nithard, I674.

65. Según el marqués de Los Balbases, estas sumas podían decantar la elección «a satisfacción de la Augustísima Casa»: AGS, Est., 2393, s. f., El marqués de Los Balbases, 8 de marzo de 1674 .

66. AGS, Est., 2393, s. f., Consejos de Estado del 28 de enero, 7 de febrero y I5 de abril de 1674 .

67. AGS, Est., 2393, s. f., D. Pedro Medrano, Madrid, 30 de abril de I674.

68. Una concisa descripción de la elección real de 1674 la encontramos en: Andrzej Adam Majewski, «Elekcja Jana Sobieskiego na tron Rzeczypospolitej w I674 roku", Almanach Warszawy, X (2016), pp. 85-93. La dieta de convocatoria, que debía marcar las bases de la elección, se desarrolló entre enero y febrero. La dieta de elección se inició a finales de abril, si bien no fue hasta el ro de mayo, con la llegada de Sobies- 
En la primera etapa, que se desarrolló durante las últimas semanas de I673 y los primeros meses de I674, el objetivo de los partidarios de la casa fue asegurar la continuidad de Leonor María de Austria como reina de Polonia. Esta disfrutaba de una gran popularidad entre ciertos sectores de la nobleza y el clero polaco - en contraste con su marido, que en el momento de su muerte apenas contaba con el aprecio de sus súbditos-, mientras aseguraba la pervivencia de la influencia austriaca en la Corte de Varsovia. La solución vino de ciertas dietinas locales - pequeñas asambleas territoriales que después enviaban a sus representantes a la Dieta general—, las cuales garantizaron que únicamente elegirían como rey a un príncipe soltero para que pudiera casarse con ella. ${ }^{69}$ Dicho compromiso, a largo plazo, no resultó ser demasiado firme, si bien en su momento sí que se consideró como un éxito en Viena, al reforzar la posición de Lorena, príncipe soltero, frente a Condé o Neoburgo, ambos casados. ${ }^{\circ}$ Del mismo modo, los lituanos, abanderados por la familia Pac, trataron de revivir una supuesta ley antigua que prohibía cualquier candidatura Piast, es decir: la elección al trono de un natural. Detrás de esta iniciativa estaba el deseo de excluir a Juan Sobieski, que se había convertido en uno de los candidatos no declarados que más preocupación despertaba en Viena. ${ }^{71}$ A pesar del buen recibimiento que tuvo la iniciativa en la dieta de convocatoria, esta solo fue respaldada de forma oral.

ki a Varsovia, cuando entró en su etapa decisiva, que culminaría con la elección de este el día 2I. El proceso concluía con una última dieta, la de coronación.

69. AGS, Est., 2394, s. f., El marqués de Los Balbases, Viena, 3I de mayo de 1674.

70. AGS, Est., 2393, s. f., D. Pedro Ronquillo, Viena, 8 de marzo de I674. Fue entonces cuando se empezó a hablar más del hijo del príncipe de Neoburgo, pues el padre, además de estar casado, tenía una nutrida prole que se temía que quisiera asentarse en Polonia; este asunto también fue tratado por Nithard en Roma, el cual, junto con los cardenales Pio y Hesse, trabajó para promover la unión del futuro rey con Leonor María: AGS, Est., 3048, El cardenal Nithard a la reina, Roma, Io de marzo de 1674.

7I. Balbases escribió, en cifrado, al conocer la iniciativa: "con que con esta suerte se sacava al general Sobieski por lo que suponía con su mando y partido, como por la inclusión que tenia en el de franceses, era el que efectivamente ocasionaba mas su duda y cuidado». AGS, Est., 2393, s. f., El marqués de Los Balbases, 8 de marzo de I674. 
La segunda etapa fue mucho más complicada e imprevisible, y correspondía con la elección real propiamente dicha. Esta se desarrolló a las afueras de Varsovia y, como ya era costumbre, congregó a una gran multitud de nobles polacos. ${ }^{72}$ El objetivo en esta ocasión era situar a Carlos de Lorena o a otro príncipe afín en el trono polaco, y medir allí la fuerza real de las diversas partes. Desde un primer momento, la Casa de Austria, y en concreto el príncipe de Lorena, contó con el apoyo de la familia Pac de Lituania, la cual estaba liderada entonces por el canciller del gran ducado, Krzysztof (I62I-I684), así como por su primo, el hetman y palatino de Vilna, Michał Kazimierz Pac (I624-I682), enemigos ambos de Juan Sobieski. Los Pac habían logrado cierta preeminencia en los últimos años respecto al resto de las familias lituanas, por lo que proclamaron que llevarían los votos de todo el gran ducado en favor de Lorena. ${ }^{73}$ El príncipe también contó con el apoyo del primado Czartoryski, así como de su familia y de una parte de la nobleza de la Gran Polonia. Sin embargo, su candidatura carecía de una cabeza visible en Polonia, y su búsqueda fue uno de los cometidos principales de Ronquillo en Varsovia.

Por otra parte, estaba la cuestión del dinero. La elección real era un negocio caro, que solía suponer un gran desembolso por parte de los candidatos y los príncipes que los respaldaban. El dinero se utilizaba para ganar votos, corromper voluntades y repartir entre partidarios. También para pagar las deudas atrasadas de la confederación. En este punto, don Pedro Ronquillo fue muy conciso: «Y así, seńor, este negocio no consiste sino en dinero, dinero, dinero». ${ }^{74} \mathrm{El}$ papel del dinero era más importante aún en aquel momento, pues los polacos debían gran-

72. Ya en las primeras elecciones del siglo xvi se había instaurado el principio Viritim, según el cual cualquier noble polaco tenía derecho a elegir sus reyes. Esto provocaba la llegada de miles de nobles, incluidas las clientelas de los grandes magnates, con la consiguiente inestabilidad y la posibilidad de que estallara un enfrentamiento armado.

73. Ya en marzo, Michał Kazimierz había anunciado el apoyo de los votos lituanos, que solían mostrar cierta cohesión en este tipo de encuentros con los polacos, a Carlos de Lorena: AGS, Est., 2393, s. f., D. Pedro Ronquillo, Viena, 8 de marzo de I674.

74. Ronquillo al marqués de Los Balbases, Varsovia, 25 de abril de I674, en RoDRÍGUeZ VILLA, Misión secreta, doc. I. 
des cantidades a su ejército, de manera que este podía decidir el futuro de la elección. Los Pac, por ejemplo, aseguraron que ganaría el trono aquel que pagara los sueldos atrasados de los soldados, que valoraban en I millón de florines. Esto era un grave obstáculo, especialmente para la candidatura de Carlos de Lorena, quien, según los informes que manejaba la embajada, solo contaba en aquel momento con 200.000 florines, además de unas joyas que trataba de empeñar sin demasiado éxito. En todo caso, una cifra del todo insuficiente, a la que había que sumar los gastos en sobornos y el dinero destinado a ser repartido entre los partidarios. Para remediarlo, el príncipe buscó el apoyo de su familiar, el príncipe de Vaudemont —quien solo pudo ofrecerle 250.000 florines en rentas, no en dinero, por lo que poco valor tuvo-, así como de su tío, el duque de Lorena. ${ }^{75}$

Dicha carencia fue una de las principales críticas que hizo Ronquillo a la candidatura de Lorena, así como a la estrategia imperial en su conjunto, que apenas contemplaba un segundo candidato en caso de que el este fallara. Además, Ronquillo cuestionaba la cohesión del bloque lituano, señalando las rivalidades que existían en su seno y, en concreto, el vínculo entre el rival de los Pac, Michał Kazimierz Radziwiłt, y Juan Sobieski, pues el primero estaba casado con la hermana del segundo. También criticó su fuerza, que juzgaba insuficiente por influencia y número para decidir la elección. ${ }^{76}$ Ronquillo, por otra parte, tenía muy presente la importancia del ejército y su posible papel en manos de Juan Sobieski. Durante aquellos meses, no dejaron de llegar a Viena numerosos informes que hablaban de un repliegue parcial de las fuerzas polacas del sur y su establecimiento en algunas ciudades clave, como Cracovia. ${ }^{77}$ Estas noticias no eran tan preocupantes de cara a la guerra

75. Para ello, envió a un agente a Hamburgo, si bien Ronquillo nunca tuvo muchas esperanzas en el apoyo de su tío. AGS, Est., 2393, s. f., Cartas de D. Pedro Ronquillo desde Viena del 8 y 22 de marzo de 1674.

76. Ibidem.

77. Según los avisos de la embajada, el ejército polaco constaba, a finales de I673, de cuarenta mil hombres, una parte importante de los mismos bajo el mando de Sobieski: AGS, Est., 2393, s. f., El marqués de Los Balbases, Graz, I de noviembre de I673. 
contra el Turco, dada la reciente irrupción de los moscovitas en Ucrania, como en la elección, puesto que, comandadas por Sobieski, podían ser utilizadas para forzar una resolución. En opinión de Ronquillo, bastaba con que el general se dirigiera con ellas a la frontera lituana para romper el bloque formado por los Pac, y solo el hecho de dejar avanzar a los turcos podía condicionar la dieta. ${ }^{78}$

En febrero de I674, Ronquillo escribió a la Corte madrileña señalando cuáles eran las claves, a su entender, para ganar la elección. Para empezar, había que satisfacer públicamente el pago de las tropas, o al menos de una parte, obteniendo así su lealtad; segundo, se debía ganar la voluntad de los particulares, recurriendo de nuevo al dinero; y por último, se debía lograr el voto firme de los ya declarados, es decir, evitar las deserciones en el campo de los partidarios. ${ }^{79}$ Una vez más, todo dependía del dinero y en su carta, el embajador también pedía a Madrid más medios. Su intención no era que se destinaran grandes sumas a la elección, dado lo hipotecada que estaba la hacienda real, pero sí disponer de alguna cantidad superior que ofrecer, en torno a 24.000 o 30.000 reales de a ocho. Además, pidió dos toisones de oro para poder entregarlos a las principales figuras del reino — una forma «barata» $y$ muy efectiva de ganar su voto, "porque en los hombres de aquella clase sería uno de los más principales atractivos por ser iguales a su rey en tan esclarecida insignia»—. ${ }^{80}$ Como argumento, señaló que tal concesión reafirmaría el propio prestigio de la Orden, al extenderla más allá de

78. AGS, Est., 2393, s. f., D. Pedro Ronquillo, Viena, 22 de febrero de I674; Ronquillo al marqués de Los Balbases, Varsovia, 25 de abril de I674, en RodrígueZ Villa, Misión secreta, doc. I. Sobre la intervención moscovita en el conflicto véase Brian L. Davies, Warfare, State and Society on the Black Sea Steppe, I500-I700, Routledge, Londres, 2007, pp. I58-162.

79. De esta forma, se quería evitar lo ocurrido en I669, cuando muchos de los declarados por Lorena, a los que ya se había pagado, abandonaron finalmente su candidatura. En palabras de Ronquillo: «pues el haver faltado esta advertencia en la ultima elección ocasiono perderla el Principe de Lorena y otros y que recaiese en la tumultuaria del difunto rey», en AGS, Est., 2393, D. Pedro Ronquillo, Viena, 22 de febrero de 1674 .

8o. AGS, Est., 2393, s. f., D. Pedro Ronquillo, 22 de febrero de 1674. 
Alemania, Italia y España. Ninguna de estas peticiones fue escuchada en Madrid.

\section{Ronquillo y su actividad en la elección real}

El embajador español partió de Viena, dejando atrás a la mayor parte de sus criados, en los últimos días de marzo a pedido del emperador, quien le instó para que lo hiciera con urgencia. ${ }^{8 \mathrm{r}}$ Tras su llegada a Varsovia, fue visitado por el confesor de la reina Leonor María, quien le comunicó el estado de la elección y concertó asimismo una audiencia secreta con esta para la noche siguiente. Ronquillo y Leonor María se reunieron al menos en tres ocasiones en los días siguientes y se estableció una buena relación entre ambos, la cual se desarrolló fundamentalmente en italiano. El español no tardó en destacar las buenas cualidades de la reina, que contaba con el apoyo de muchos nobles y que siempre se mostró dispuesta a recibirlo. Es más, esta se comprometió a seguir únicamente el consejo de sus hermanos - a través de sus representantes-, fiando por completo su futuro a la decisión de Leopoldo I. El embajador español se excusó de hacer más visitas a otros ministros extranjeros, como los de Suecia y Dinamarca, por temor a que surgieran conflictos de precedencias con el representante francés. ${ }^{82}$

Uno de los asuntos a los que más atención prestó Ronquillo durante los primeros días fue la búsqueda de una cabeza visible en Polonia para la candidatura de Lorena. Según la reina, el príncipe contaba con grandes apoyos entre la nobleza media, en parte gracias a ella, pero estos tenían visos de perderse si no había ningún grande del reino que se declarara a su favor. El hombre favorito para cumplir esta función, tras consultarlo con el embajador Schaffgotsch, fue Dymitr Jerzy Wiśniowiecki (I63I-1682), familiar del rey difunto. Wiśniowiecki había desa-

8I. AGS, Est., 2393, s. f., D. Pedro Ronquillo, Viena, I de abril de i674. Para los pormenores de este viaje véase ScotT, SKWARCZYŃski, "A I7th-Century Spanish».

82. Ronquillo al marqués de Los Balbases, Varsovia, 25 de abril de I674, en RoDríguez VIlla, Misión secreta, doc. I. 
rrollado una gran rivalidad con Juan Sobieski en el campo militar, donde sus carreras habían ido a la par. Durante el reinado anterior, por ejemplo, la Corte de Miguel I había tratado de promocionar a Dymitr Wiśniowiecki en un intento vano por contraponer su figura a la del hetman dentro del ejército. No obstante, ambos hombres se habían reconciliado públicamente a principios de I67I, cuando Dymitr se casó con una sobrina de Sobieski. ${ }^{83}$ La intención de Ronquillo, así como la de la diplomacia imperial, era tantear lo férrea que era esta reconciliación ofreciendo a Wiśniowiecki el liderazgo de la candidatura de Lorena. Es probable que tras esta iniciativa estuviera el deseo de obtener una posición de fuerza dentro el ejército, dado el prestigio de que disfrutaba Dymitr entre algunas de sus filas; así como de atraerse a los Potocki, familia con la que estaba vinculado. Tras un primer encuentro, el noble se mostró dispuesto a cooperar, siempre y cuando antes le fuera pagada una suma por adelantado — una actitud que Ronquillo reprochó encarecidamente en sus cartas——. ${ }^{84}$ Así estaban las cosas cuando Florian Czartoryski murió, lo que supuso el abandono de todo intento de ganar a Wiśniowiecki.

Durante esos mismos días se planteó otra posibilidad, esta vez a instancias del nuncio: la de ganarse al propio Juan Sobieski para la candidatura de Lorena. Durante semanas se había especulado mucho sobre la posible actitud que podría adoptar el hetman tras su llegada a la Dieta. Este mantenía estrechos contactos con los franceses y sus partidarios, empezando por el tesorero del reino, Andrzej Morsztyn. Todo parecía apuntar a que, como la vez anterior, respaldaría al príncipe de Condé como rey, o se plegaría a las instancias de Luis XIV en favor de Neoburgo. La candidatura de Condé, sin embargo, suponía grandes riesgos, dada la férrea oposición que había entre algunos polacos, lo cual podía hacer estallar un conflicto civil. El nuncio, en cambio, creía

83. Sobre esta rivalidad: Zbigniew Hundert, «Jan Sobieski przeciw Dymitrowi Wiśniowieckiemu, czyli konflikt dwóch hetmanów koronnych w latach I668-I670. Zarys problematyki», Teka Historyka, 45 (2012), pp. I26-138.

84. D. Pedro Ronquillo al marqués de Los Balbases, Varsovia, II de mayo de i674, en Rodríguez Villa, Misión secreta, doc. 2. 
poder ganar la voluntad de Sobieski si se le ofrecían las contrapartidas suficientes — que eran, en su opinión, la entrega de mercedes tanto del emperador como del rey de España, el título de príncipe del Imperio y un toisón de oro- $-y$, sobre todo, si se ganaba a su esposa, quien guiaba gran parte de sus ambiciones. Ronquillo se mostró muy escéptico ante esta alternativa, porque entendía que Sobieski solo apoyaba a Condé como una estrategia para abrirse camino, siendo su objetivo final el hacerse él mismo con el trono. Así parecían indicarlo algunas de las noticias que le habían llegado últimamente, en las que se hablaba de cómo el hetman estaba buscando sus propios partidarios. Además, en aquel momento el embajador consideraba muy prematuro y arriesgado declararse tan abiertamente en favor de Lorena, y abogó, en cambio, por la defensa a ultranza de los intereses de la reina en Polonia, "pues asegurados estos, corre seguro el juego por Lorena». ${ }^{85}$

El desarrollo de los acontecimientos se empezó a acelerar a partir del ro de mayo, tras la llegada de Sobieski a Varsovia. Durante los días siguientes, los representantes de los príncipes hicieron sus ofrecimientos a los electores, mientras que los de Lorena trataban de ganarse a algunos electores, sobre todo nobles de renombre. De esta forma, se entregaron 5.000 húngaros a varios miembros de la familia Potocki, y otros I.OOo al mariscal de la dieta. ${ }^{86}$ Pero todo cambió el día I5 de mayo, cuando el primado Florian Czartoryski murió, de manera que quedó totalmente desamparada la candidatura de Lorena, la cual ni siquiera

85. Ronquillo al marqués de Los Balbases, Varsovia, 25 de abril de I674, en RoDRíguez VIlla, Misión secreta, doc. I. De la misma opinión era el embajador imperial, que evitó las declaraciones públicas en favor de Lorena: Woliński, "Poselstwo Krzysztofa Schaffgotscha». Hay que señalar que la opción de ganarse a Sobieski no solo fue planteada por Buonvisi, sino también por otras diplomacias, como la de Brandeburgo: KAMIEŃSKI, «Działania dyplomacji»; sobre las propuestas que se hicieron, basadas fundamentalmente en fuentes francesas, véase: WALISZEwski, Archiwum spraw, I, pp. 28-36.

86. D. Pedro Ronquillo a la reina gobernadora, Varsovia, 26 de mayo de 1674 [carta publicada por Rodríguez Villa en Revista Europea, 30 (20 de septiembre de I874), pp. 37I-380]; encontramos las propuestas de Lorena y Neoburgo en KAMIEŃsKI, «Działania dyplomacji». 
contaba por entonces con una cabeza visible. Para evitar una desbandada general, Ronquillo tuvo que ofrecer los 3.000 húngaros de los que antes hacíamos referencia, y logró mantener el bloque lituano con dificultad. ${ }^{87}$ Entretanto, Sobieski actuó con suma habilidad, repartiendo I80.000 reales de a ocho entre los electores polacos, según las cifras que manejó Ronquillo. Al mismo tiempo, su esposa, María Casimira, trabajó por obtener el apoyo del embajador francés. ${ }^{88}$ A pesar de todo, el resultado de la primera votación siguió dando cierta ventaja a Lorena, quien contó con el respaldo de doce palatinos —el resto quedó dividido entre Condé, Neoburgo y el propio Sobieski-. Pero esta votación solo benefició al hetman, que aglutinó el voto de los otros dos, así como el apoyo del obispo de Marsella, que ante la perspectiva de ver elegido a Lorena, y como mandaban sus instrucciones, prometió el apoyo de Luis XIV para Sobieski. En cuanto al bloque lituano, como ya había apuntado Ronquillo, no resultó ser demasiado firme: fue roto primero por Michał Kazimierz Radziwiłł y sus más allegados, y más tarde por otros nobles a los que Sobieski logró convencer. Poco después, cuatro obispos fueron a visitar a la reina para consultarle su parecer y preguntarle por su candidato favorito. Pero esta, muy prudente y preocupada por la futura relación entre el nuevo monarca y su familia, evitó pronunciarse, afirmando que se plegaría por completo a los deseos generales de los nobles. El día 2I, Sobieski fue proclamado rey. El juicio de Ronquillo fue del todo inequívoco: «Señor mío, cuanto mala podía ser la elección así ha sucedido». ${ }^{89}$

87. D. Pedro Ronquillo al marqués de Los Balbases, Varsovia, I6 de mayo de I674, en Rodríguez Villa, Misión secreta, doc. 4.

88. Sobre el papel de María Casimira en la elección y sus encuentros con el obispo de Marsella véase Izabela KARWAT, «Rola Marysieńki w wyniesieniu do tronu Jana III», en F. Kubiaczyk, M. Kubiaczyk, Pteć i wtadza w kontekstach historycznych i wspótczesnych, Instytut Kultury Europejskiej, Gniezno, 20I4, vol. I, pp. 337-349.

89. D. Pedro Ronquillo al marqués de Los Balbases, Varsovia, 2I de mayo de I674, en Rodríguez Villa, Misión secreta, doc. 6. 


\section{Las consecuencias de la elección: Ronquillo en Toruń}

Unos días más tarde, el embajador resumía el resultado de la elección a la reina Mariana en unos términos muy similares:

Esta elección ha sido rara, y una demostración evidente de la vileza, codicia y cobardía desta gente, pues son muy pocos los que no conocen el daño y riesgo de esta elección, la injuria hecha a una tan grande señora como la Reina, y la ruina de la patria o de la libertad..$^{\circ}$

El ascenso de Sobieski fue del todo adverso para los intereses de la Casa de Austria, así como de los otros príncipes de alrededor. El nuevo rey planeaba dar un giro total a las relaciones de Polonia con el exterior, abogando por una aproximación a Francia y una nueva política en el Báltico. ${ }^{91}$ Además, recogía la herencia reformista del antiguo grupo de corte y no eran pocos los que pensaban que, con el apoyo del ejército, trataría de reformar el sistema político para consolidar el principio monárquico. ${ }^{92}$ En resumen: una política contraria a las cortes de Viena, Berlín y Moscú, que no tardaron en tomar medidas para oponerse.

Poco después de conocerse el resultado de la elección, se empezó a plantear en Viena una posible intervención militar en favor de los que se oponían a Sobieski: sus más férreos enemigos en Polonia y los Pac de Lituania. La mayor impulsora de esta iniciativa era la emperatriz viuda Leonor Gonzaga-Nevers quien, junto con otros ministros, denun-

90. D. Pedro Ronquillo a la reina gobernadora, Varsovia, 26 de mayo de 1674 [carta publicada por Rodríguez Villa en: Revista Europea, 30 (20 de septiembre de I874), pp. 37I-380].

9I. Kazimierz Piwarski, «La Pologne et la question baltique dans la deuxième moitié du Xvire siècle», en La Pologne au VIIe Congrès International des Sciences Historiques, Sociéte Polònaise d'Histoire, Varsovia, I933, vol. II, pp. 85-94.

92. Entre ellos estaba Ronquillo, que poco después escribiría a Lira: «El rey se ve no poco cuidadoso en el establecimiento de su nuevo gobierno acomodarse con el exercito para que haviendole hecho este poder y a mi parecer de Rey con el mismo se constituya en estado Monarchico y por esta razón es muy probable que dilata su coronación». AGS, Est., 8488, f. 400, D. Pedro Ronquillo a Lira, 6 de julio de I674. 
ció algunas irregularidades en el proceso electivo, como que los nuncios enviados por las dietinas faltaran a su palabra de elegir a un príncipe soltero. En contra de la intervención estuvo el marqués de los Balbases, que temía la apertura precipitada de un nuevo frente que pudiera afectar al del Rhin. Además, Balbases veía sobrados motivos para no emprender tal acción. Al fin y al cabo, Sobieski había contado con el respaldo mayoritario de los polacos y mantenía al ejército bajo control. Solo en Cracovia, ciudad a la que debía acudir para coronarse, el general tenía situados a cuatro mil hombres. Por otra parte, la oposición carecía de un líder declarado, por lo que una intervención no parecía conveniente. En vez de ello, el marqués aconsejó contemporizar y mantener viva a esta oposición a la espera de que se presentara una ocasión mejor. ${ }^{93}$ De la misma opinión fue el embajador Schaffgotsch, considerado en Viena como un experto en los asuntos polacos; este recibió poco tiempo después la orden de felicitar al nuevo rey en nombre de Leopoldo, o lo que era lo mismo, darle su reconocimiento, descartándose así una intervención a corto plazo. Entre los motivos que más tarde se esgrimieron, estaba el poco apoyo que habría tenido tal acción por parte de los polacos, así como los muchos recursos que Leopoldo ya tenía desplegados en el Rhin. En cualquier caso, el emperador trató de presentar su decisión como otro signo de solidaridad hacia la Corte de Madrid, desamparando en cambio a la emperatriz viuda. ${ }^{94}$

Durante los meses siguientes, pareció que el statu quo de la zona podía verse totalmente alterado tras el ascenso del nuevo rey. Nada más conocerse la noticia de la elección, los húngaros volvieron a hacer movimientos, por lo que Leopoldo tuvo que enviar más tropas a la zona para contenerlos. ${ }^{95}$ Pero la atención durante las semanas siguientes estuvo centrada en el representante de Luis XIV en la zona, Forbin de

93. AGS, Est., 2394, s. f., Consejos de Estado del I3 y 24 de julio de I674.

94. «Anteponiendo el servicio de su Majestad a la queja de la señora emperatriz», en AGS, Est., 2394, s. f., El marqués de Los Balbases, I4 de junio de 1674; D. Pedro Ronquillo al marqués de Los Balbases, Varsovia, 2I de mayo de I674, en RodríGuez Villa, Misión secreta, doc. 6.

95. AGS, Est., 2394, s. f., Consejo de Estado del 24 de julio de 1674. 
Janson, quien trató de establecer un acuerdo de paz con la Puerta Otomana, al mismo tiempo que animaba a los polacos a emprender acciones en Silesia y Hungría. ${ }^{66}$ Su labor sería continuada posteriormente por el marqués de Bethune, hermano de la reina María Casimira, nombrado nuevo embajador de Luis XIV en Varsovia. ${ }^{77}$ En agosto, Ronquillo comunicó a Lira las supuestas negociaciones entre los representantes de Francia y Suecia y el tesorero del reino Morsztyn, que tenían como objetivo la creación de una alianza contra Moscovia y la intervención de doce mil hombres en Hungría..$^{8}$ En junio de 1675 , Sobieski firmó un primer acuerdo secreto con los franceses: el Tratado de Jaworów, que proyectaba una intervención futura en la Prusia ducal con ayuda del Rey Sol. ${ }^{99} \mathrm{El}$ ascenso al trono de Sobieski también afectó en Roma, tras nominar el rey para el capelo al obispo de Marsella, todo un premio a sus servicios durante la elección. ${ }^{100}$ En poco tiempo, la corte de Varsovia cambió por completo, llenándose de franceses y ministros afines, que celebraban sin demasiados escrúpulos los éxitos militares de Luis XIV en Flandes y Borgoña.

Frente a esta situación, la corte de Viena tomó medidas y entró en contacto con los embajadores de Moscovia, mientras daba instrucciones al conde de Harrach para conferir un mayor impulso a las negociaciones entre los representantes de Carlos II y el elector de Brandemburgo. Según Harrach, este sería el mejor medio de atajar todos los males:

96. Las sospechas sobre este embajador fueron muy anteriores a la elección de Sobieski: AGS, Est., 2393, s. f., D. Pedro Medrano, Madrid, I6 de mayo de I674. Jean BÉRENGER, "Alliances de revers et coopération militaire au XVIIe siècle: la politique française en Europe orientale», en D. Tollet, L. Belly, eds., Guerres et paix en Europe, pp. 345-360.

97. AGS, Est., 2394, s. f., El marqués de Los Balbases, 6 de noviembre de 1674.

98. AGS, Est., 8488, f. 406, D. Pedro Ronquillo a Lira, Toruń, I8 de agosto de 1674 .

99. WójcıK, «Jean Sobieski: du politicien».

Ioo. Según Nithard, los mayores perjudicados de esta decisión eran los españoles, por lo que trabajó para bloquear el nombramiento o, en su defecto, para que se nombrara a un segundo cardenal afín. AGS, Est., 3048, El cardenal Nithard a la reina, Roma, 8 de septiembre de 1674 . 
Que confinando con Polonia podrá siempre ayudar a contener aquellos animos en la linea de la razón y ser medio de conservar la buena correspondencia con los moscovitas. ${ }^{\text {IOI }}$

En julio de 1674 , la Corte española expidió órdenes a sus ministros para que tuvieran dinero dispuesto para asistir económicamente a Federico Guillermo y sus ejércitos. ${ }^{\mathrm{IO} 2}$ Asimismo, se consideró prudente el bloqueo de las Décimas eclesiásticas, algo en lo que estuvo de acuerdo Leopoldo I. Entre los motivos que se esgrimieron figuraba la preocupación que despertaban en Madrid las recientes negociaciones entre el obispo de Marsella y los enviados del sultán, que podían derivar en una grave amenaza sobre Hungría e Italia. ${ }^{103}$ Es más, en una orden discreta, la corte escribió a Balbases y Ronquillo para que, en lo que pudieran, trataran de fomentar la guerra polaco-turca. ${ }^{104}$ Asimismo, se pidió una declaración escrita a Leopoldo en la que se detallara el número de fuerzas que dejaría en el Rhin en caso de una ruptura en Hungría. ${ }^{\text {Ios }}$

A estas medidas de carácter internacional, se sumó la injerencia austriaca dentro del Reino de Polonia, en la que jugó un papel clave la reina Leonor María. Esta se había retirado a las afueras de Varsovia tras conocer la elección de Sobieski, y se había establecido a continuación en la ciudad de Toruń con una pequeña corte. Para entonces la reina seguía fiando su futuro a la decisión de su hermano, mientras que su

IOI. Sobre las negociaciones con Moscovia véase AGS, Est., 2394, s. f., Consejo de Estado, el marqués de Los Balbases, Viena, Is de diciembre de 1674; ibidem, 3 I de diciembre de i674. Sobre la negociación con Brandeburgo véanse AGS, Est., 2394, s. f., El conde de Harrach, Madrid, II de julio de 1674; idem, Consejo de Estado, 24 de julio de I674.

I02. AGS, Est., 2487, s. f., Carta al duque de Alburquerque, Madrid, 9 de agosto de I674.

I03. AGS, Est., 2394, s. f., El marqués de Los Balbases, Viena, 28 de junio de I674; idem, Consejo de Estado, I2 de agosto de I674.

I04. AGS, Est., 2487, s. f., Carta al marqués de Los Balbases, Madrid, is de agosto de I674; AGS, Est., 2394, s. f., Consejo de Estado, I3 de julio de I674.

I05. AGS, Est., 2487, s. f., La reina Mariana al marqués de Los Balbases, Madrid, I6 de julio de I674. 
madre seguía presionando en Viena para una intervención. Pero, a pesar de que esta nunca se llegó a materializar, la reina se mantuvo en Polonia, convirtiéndose en un foco de influencia austriaca dentro de aquel reino. ${ }^{\mathrm{I} 6}$ Junto a ella estuvo en todo momento don Pedro Ronquillo, quien se integró en su séquito, participó en sus ceremonias e incluso organizó algunos festejos. ${ }^{107}$

Sin embargo, con el devenir de los meses, el ánimo de aquella corte se fue enrareciendo, en parte por la falta de medios. En junio, el marqués de los Balbases había cuantificado las rentas de la reina en 40.000 reales de a ocho, una cifra insuficiente para mantener el decoro. ${ }^{108}$ Para remediarlo, el conde de Harrach había solicitado a la reina Mariana una pensión para su hermana, una demanda que tuvo que ser desestimada por la falta de medios. ${ }^{109}$ Para septiembre, los problemas ya eran más que evidentes y surgieron los primeros desacatos entre el servicio de la reina por la falta de pagas. ${ }^{\text {Iо }}$ A ello había que sumar los constantes rumores que apuntaban a un posible atentado contra la vida de Leo-

I06. AGS, Est., 2394, s. f., El marqués de Los Balbases, Viena, 3I de mayo de 1674. 107. Conocemos bien cómo fueron estas fiestas gracias a las cuentas que posteriormente dejó Ronquillo. De esta forma, sabemos que el 30 de mayo de I674 pagó 447 escudos por un festín para el cumpleaños de la reina, que tuvo que costear ante la ausencia del representante imperial; a la celebración acudieron muchos de los partidarios de la casa. El 26 de julio volvió a celebrar otra fiesta entre las damas de la reina, en este caso menor, de 116 escudos ("una merienda que di a las damas y la corte de la dicha reyna»). Por último, el 6 de noviembre, en Toruń, organizó una misa y sermón con los jesuitas de la ciudad para celebrar el cumpleańos de Carlos II, seguidos de comida, baile y cena; acudió lo más excelso de la nobleza de la Gran Polonia y Prusia, así como los principales partidarios de Lituania. El coste total de esta celebración fue de 782 escudos: AHN, Est., I294, ff. 49 y ss, «Relación jurada y firmada de los gastos secretos y extraordinários que yo Don Pedro Ronquillo he hecho por el real servicio de su majestad en el ministério de embiado extraordinário a Polonia desde primero de marzo de mil setecentos y tetenta y quatro que pase a aquel empleo hasta fin de mayo de 1675 que pase a Inglaterra».

I08. AGS, Est., 2394, s. f., El marqués de Los Balbases, Viena, I4 de junio de 1674.

I09. AGS, Est., 2487, s. f., La reina al marqués de Los Balbases, Madrid, 7 de noviembre de 1674 .

iı. D. Pedro Ronquillo al marqués de Los Balbases, Toruń, 4 de septiembre de 1674, en Rodríguez VilLa, Misión secreta, doc. I2. 
nor, detrás de los cuales se solía señalar a la esposa de Sobieski, María Casimira, de quien decían que había estado detrás de la muerte de su primer marido. ${ }^{\mathrm{III}}$ En este contexto, Ronquillo juzgó insostenible la permanencia de la exreina y aconsejó su marcha inmediata. De hecho, en octubre, ante la llegada de nuevas noticias sobre una posible amenaza contra su vida, recomendó su partida urgente a Silesia y propuso que dejara la casa puesta, junto con su tesoro y unos criados, para que su marcha no pareciera definitiva. ${ }^{\text {II2 }}$ Pero esta permaneció en Toruń, a expensas de lo que decidiera su hermano Leopoldo, quien se embarcó en nuevas conversaciones matrimoniales para casarla con el rey de Suecia, que tampoco llegaron a ninguna parte. ${ }^{\mathrm{II}}$

Este clima de abandono también se extendió al propio Ronquillo, que a pesar de haber sido ya nombrado embajador de Inglaterra, seguía esperando los pagos atrasados y las ayudas de costa para poder emprender su viaje. En noviembre, el embajador escribió al marqués de los Balbases quejándose y asegurando que, si encontraba a alguien que le comprara su coche, lo vendería para salir del reino, aunque fuera a pie. Tal exageración no fue necesaria, si bien al final tuvo que pagar de su propio bolsillo su salida. ${ }^{\mathrm{II}}$ Antes de marchar, se reunió una vez más con Leonor María, quien le rogó que mediara ante su hermana «para sacar-

III. Al fin y al cabo, Leonor María Josefa todavía representaba un obstáculo para su coronación, dado que había dos reinas: la austriaca — que contaba con fuertes partidarios- y María Casimira — que, por su condición de francesa y por su carácter, era menos apreciada por los polacos- Al menos así lo describió Ronquillo, quien no dudaba en llamarla «la ruin francesa». D. Pedro Ronquillo a Balbases, Varsovia, 2I de mayo de 1674, en Rodríguez Villa, Misión secreta, doc. 6.

II2. D. Pedro Ronquillo al marqués de Los Balbases, Toruń, 2 octubre de I674, en Rodríguez Villa, Misión secreta, doc. 20.

II3. Estas conversaciones eran un intento postrero de evitar la entrada de Suecia en la guerra del bando de Francia. Sobre las mismas: AGS, Est., 2393, s. f., El marqués de Los Balbases, Viena, I5 de noviembre de 1674; AGS, Est., 2394, s. f., El marqués de los Balbases, Viena, I8 de octubre de I674; ibidem, Consejo de Estado, 4 de diciembre de 1674 .

II4. Cartas de Ronquillo al marqués de Los Balbases desde Toruń del 6 y del I2 de noviembre de i674, en Rodríguez Villa, Misión secreta, docs. 2I y 22. 
la de la desgracia de estar en Polonia». Lo cierto es que para entonces su situación se estaba tornando crítica, por lo que declaró que, si Leopoldo no le permitía marchar, entraría en alguna orden religiosa, o cedería a un «matrimonio violento». Como sabemos, este aún tardaría un tiempo en establecerse, pues no fue hasta principios de 1678 cuando se casó con Carlos de Lorena, convertido ya en duque. Como agasajo antes de partir, la reina dio al embajador una sortija, así como un retrato que, por motivos de etiqueta, fue dirigido a su hermana y no a él. ${ }^{\text {IIs }}$

\section{Conclusión: ¿un triunfo francés?}

A medio plazo, la elección de Sobieski tuvo un impacto limitado en el escenario occidental. A finales de agosto de 1674, se conoció en Viena el fracaso de las conversaciones de paz polaco-turcas auspiciadas por la diplomacia francesa, lo que causó no poco alivio en esta corte, así como en Madrid. ${ }^{116}$ Poco después, Sobieski tuvo que marchar hacia el sur, junto con su ejército, y se enfrentó durante las semanas siguientes a los turcos y los tártaros en una serie de encuentros en los que, una vez más, cosechó notables éxitos. La continuidad de la guerra polaco-turca, que se prolongó hasta finales de 1676, impidió a Sobieski emprender ninguna acción de envergadura en Silesia y Prusia, como habría deseado. Además, el monarca tuvo que tener presente la resistencia mostrada por la oposición, que se mantuvo particularmente activa en los territorios de Lituania y Sandomierz. Esta recibió el apoyo durante los ańos siguientes de las cortes de Viena y Berlín y, en palabras de Ronquillo, «aunque esto no será de suerte que le aya de quitar la corona, por lo menos le dara cuidado hasta ajustar la perfecta obediencia»."177 Ambos

II5. D. Pedro Ronquillo al marqués de Los Balbases, 8 de diciembre de I674, en Rodríguez Villa, Misión secreta, doc. 24.

II6. AGS, Est., 2394, s. f., El marqués de Los Balbases, Viena, 23 de agosto de 1674.

II7. AGS, Est., 8488, f. 404, D. Pedro Ronquillo a Manuel de Lira, Toruń, I4 de agosto de I674; ibidem, f. 408, Ronquillo a Lira, Toruń, 4 de noviembre de I674. Esto resultó premonitorio, pues hubo una conspiración contra el rey frustrada en $\mathrm{I} 678$. 
elementos fueron claves a la hora de retrasar la entrada de Polonia en la contienda occidental, frustrando las aspiraciones bálticas de Sobieski, a pesar de haber llegado este a un acuerdo secreto con los suecos en el verano de 1677 para atacar Prusia. ${ }^{118}$ Todo ello permitió a Leopoldo centrarse en occidente y continuar la guerra con Francia. De hecho, en octubre de I674, este desterró al príncipe de Lobkowicz de Viena. ${ }^{\text {II }}$

La paz de Nimega marcó el inicio de un cambio progresivo de alineamiento de Sobieski hacia la Casa de Austria, que se vio culminado en I683 con la liberación de Viena. Sin embargo, este viraje ya había sido pronosticado con anterioridad desde diferentes partes. Antes de marchar de Polonia, Ronquillo recibió la orden de felicitar al rey por su elección en nombre de Carlos II. ${ }^{20}$ Esta fue una labor ingrata para el embajador, que se vio obligado a emprender un largo viaje con los medios ya muy ajustados. Además, Ronquillo temía que los partidarios de Francia pudieran propiciar algún desaire protocolario, e incluso tenderle una trampa en el camino. ${ }^{\text {22I }}$ Para preparar su llegada, el embajador envió por delante a un agente suyo, Bernardo Scagnetti, quien halló al rey en Pilaszkowice, cerca de Lublin. La descripción que este hizo de su corte no fue en absoluto alentadora: Sobieski se hallaba rodeado de partidarios de Francia, quienes vestían con prendas de aquel país y se comunicaban con frecuencia en esa lengua. Es más, el monarca no quiso concretar un lugar para que Ronquillo pudiera realizar su jornada, ya que marchaba con urgencia a la guerra, y allí no sabía dónde iba a residir. Esto dio motivo suficiente a Ronquillo para dar media vuelta y regresar a Toruń. Scagnetti también encontró en la Corte a algunos partidarios de la Casa de Austria, como al antiguo limosnero de la reina

II8. Zbigniew Wójcıк, «Polish Diplomacy at the Time of the Elective Kings (1572-1699)", en G. Labuda, W. Michowicz, eds., The History of Polish Diplomacy, $X$-XXc., Sejm Publishing Office, Varsovia, 2005, pp. 70-I75.

II9. AGS, Est., 2394, s. f., Copia del decreto de S. M. Ces. al príncipe de Lobkowicz, Viena, I6 de octubre de 1674.

I20. AGS, Est., 2393, s. f., Consejo de Estado, 26 de mayo de 1674.

I2I. Cartas de D. Pedro Ronquillo al marqués de Los Balbases desde Toruń, 4 y II de septiembre de I674, en Rodríguez Villa, Misión secreta, docs. I3 y I4. 
Leonor, quien, en confidencia, le aseguró que la actitud fría del monarca se debía únicamente al círculo francés que le rodeaba. ${ }^{122}$

Aquella relación pareció confirmar las noticias que ya llegaban a Ronquillo desde diferentes partes y que hablaban de Sobieski como un partidario de Luis XIV en Europa. Pero el embajador también observó una serie de elementos que le llevaron a ser optimista. Ya en el pasado, tras su elección, el español había destacado las buenas cualidades del monarca, en concreto su "galantería" y sus grandes dotes militares. En una ocasión, incluso había llegado a asegurar que sería un gran rey para la Casa de Austria, si no fuera porque estaba casado con una francesa. ${ }^{123}$ De hecho, era precisamente María Casimira quien, en su opinión, impedía el acercamiento entre el rey y la dinastía austriaca, por lo que no es de extrañar que durante los meses siguientes estuviera tan atento a la salud de la reina. Antes de abandonar definitivamente el reino, en diciembre, el embajador señaló dos medios que, creía, podían servir para congraciarse con Sobieski, en un intento de iniciar un acercamiento. Para empezar, se debía sacar cuanto antes a la reina Leonor de Polonia. Y, a continuación, se debía apoyar a Sobieski en la guerra contra el Turco con algún dinero. ${ }^{124}$ Ronquillo solo erró en un punto de su juicio: el papel jugado por la reina, puesto que a largo plazo María Casimira sería determinante en el giro que experimentó la política exterior de Sobieski durante la década de I680. ${ }^{125}$

La misión de Ronquillo puede ser vista como un canto de cisne del papel jugado por la Monarquía en Centroeuropa. En julio de 1674, mientras el embajador se instalaba en Toruń, estallaba en Sicilia la re-

I22. D. Bernardo Scagnetti a D. Pedro Ronquillo de vuelta de la corte de Polonia, en Rodríguez Villa, Misión secreta, doc. 17.

I23. «Y si la mujer muriera, que no es muy difícil, según ella está, tuviera ocasión el señor Emperador de sacar por casamiento los más ventajosos partidos que jamás ha hecho la Polonia a la Casa de Austria»: Cartas de D. Pedro Ronquillo al marqués de Los Balbases, Varsovia, 21 y 30 de mayo de 1674, en Rodríguez VIlla, Misión secreta, docs. 6 y 7 .

I24. D. Pedro Ronquillo al marqués de Los Balbases, Lissa, 8 de diciembre de I674, en Rodríguez Villa, Misión secreta, doc. 24.

I25. SERWAŃSKI, «Être une reine étrangère». 
belión de Mesina, la cual alteró por completo los planteamientos estratégicos seguidos hasta entonces por la Monarquía en Europa. Se abría así un nuevo frente en la guerra occidental, que puso en peligro toda la estructura de poder establecida por los españoles en Italia. Esto modificó las prioridades de la corte madrileńa y afectó a su papel en la política centroeuropea. Además, gran parte de su influencia en la zona se sustentaba en los recursos provenientes de los territorios italianos, que ahora eran desviados hacia el sur para contener la rebelión. Ya en octubre de 1674, el Consejo de Estado estudió la incapacidad de seguir haciendo frente a los pagos que se habían comprometido con Leopoldo, de los que se adeudaban ya varios meses. ${ }^{126}$ Por otra parte, desde la corte española se empezó a reexaminar el valor de la alianza austriaca tras las campañas que siguieron al año i674, en las que los territorios de la Monarquía sufrieron el peso de la agresión francesa, sin que Leopoldo I ni ninguno de sus otros aliados del Imperio enviaran ayudas de consideración. ${ }^{127}$ Todo ello terminó por afectar el ánimo de la corte madrileña y condujo a una reorientación general de su política exterior, encarnada más tarde por Juan José de Austria. ${ }^{128}$ Esta fio la defensa de Italia a la creación de una liga entre sus príncipes que, si bien tenía a Luis XIV en su mira, también contemplaba muy de cerca la agresión otomana, ahora que la guerra polaco-turca tenía visos de concluir. ${ }^{29}$

I26. AGS, Est., 2394, s. f., Consejo de Estado, I4 de octubre de I674. Algo parecido ocurrió con las pensiones, sin que se redujera el número de pretendientes. En septiembre de 1674, por ejemplo, se estudió una para Carlos de Lorena: AGS, Est., 2394, s. f., Consejo de Estado, io de octubre de I674. La rebelión de Mesina había sido el motivo principal esgrimido por Mariana para no otorgar una pensión a su hermana Leonor.

I27. Antonio José Rodríguez Hernández, «El precio de la fidelidad dinástica: colaboración económica y militar entre la monarquía Hispánica y el Imperio durante el reinado de Carlos II", Studia Historica. Historia Moderna, 33 (20II), pp. I4I-I76.

I28. Sobre los sucesos durante estos últimos años y la negociación de Nimega véase Ochoa Brun, Historia de la diplomacia española, vol. viII, pp. IIO-II4.

I29. AGS, Est., 2487, s. f., D. Pedro Medrano al marqués de Los Balbases, Madrid, 25 de diciembre de 1674 . 